\title{
Türkiye'deki Görsel İletişim Tasarımı Bölümlerine Öğrenci Alımında Uygulanan Sınavlar Hakkında Öğretim Elemanı Görüşleri*
}

Arş. Gör. Zeliha Kayahan

Prof. Dr. Alev Çakmakoğlu Kuru

\section{Özet}

Sanat; bireyin varoluşunda güzel olan ne varsa ortaya çıkarmaya yarayan en etkili yoldur. Doğru sanat eğitimi alan birey doğal bir süreç ile ilk önce yakın çevresini sonrasında da toplumu daha iyi olana taşır. Bu bağlam ile sanat eğitimi içinde yaşadığımız çağın en önemli eğitim alanlarından birini oluşturur. Bu araştırmanın genel amacı, Türkiye'deki Görsel Illetişim Tasarımı Bölümü öğretim elemanlarının özel yetenek sınavı ve merkezi sınav sistemi ile öğrenci alımları hakkındaki görüşlerini öğrenmektir. Araştırmanın problemini çözmeye yönelik 5 'li likert tipi anket uygulaması yapılmıştır. Özel Yetenek Sınavı ve Merkezi Sınav Sistemi ile yerleştirilen öğrencilerin mevcut durumları ile ilgili öğretim elemanı görüşlerinin belirlenmesi amacı kapsamında, Türkiye'deki Görsel İletişim Tasarımı Bölümü öğretim elemanlarından veriler toplanmıs ve bu veriler betimsel yöntemle ele alınmış ve frekans analizi tekniği ile analiz edilmiştir. Araştırma ile Türkiye'deki Görsel Illetişim Tasarımı Bölümü öğretim elemanlarının bölümün vizyon ve amaçları göz önüne alındığında öğrenci alımlarının yetenek sınavı ile gerçekleşmesinin daha başarılı sonuçlar elde edileceği görüşünde olduğu sonucuna ulaşılmıştır.

Anahtar Kelimeler: Sanat Eğitimi, Görsel Illetişim Tasarımı, Özel Yetenek Sınavı.

\section{OPINIONS OF ACADEMICIANS REGARDING THE EXAMINATIONS APPLIED IN STUDENT ADMISSION TO DEPARTMENTS OF VISUAL COMMUNICATION DESIGN IN TURKEY}

\begin{abstract}
Art is the most effective way to reveal whatever beautiful is in the existence of individual. With a natural process, the individual who had an accurate art education, takes its close environment at first and then the society to the better. With this context, the art education constitutes one of the most important educational areas of the current era. General purpose of this study is to learn the opinions of academicians of Visual Communication Department on admission of students by special talent examination and by central examination system. Likert type with 5 survey application was made to solve the problem of research. Within the scope of determining the opinions of academicians regarding the current situations of students who were admitted by special talent examination and Central examination system, data were collected from academicians of Visual Communication Design Department and these data were analyzed by descriptive method and frequency analysis technique. With the research, it was concluded that academicians of Visual Communication Department in Turkey had the opinion that student admissions made by talent test would yield better results considering the vision and purposes of the department.
\end{abstract}

Keywords: Art Education, Visual Communication Design, Special Talent Examination.

Arş. Gör. Zeliha Kayahan, Gazi Üniversitesi.Temel Sanat Bilimleri Bölümü, Ankara.

E-posta: zelihakayahan@gazi.edu.tr

Prof. Dr. Alev Çakmakoğlu Kuru, Gazi Üniversitesi.Güzel Sanatlar Eğitimi Bölümü, Ankara.

E-posta: alevkuru@gazi.edu.tr

* Bu araştırma Gazi Üniversitesi Eğitim Bilimleri Enstitüsünde araştırılmakta olan “Türkiye'deki 


\section{Giriş}

Genel anlamda günümüzde sanat alanlı (Sanat eğitiminin verildiği ve uygulandığı) fakültelerde çevreye karşı duyarlı, paylaşmasını bilen, duygu, düşünce ve eylemlerinde girişimci olabilen, yaratıcı, kendine güvenli insan tipi yetiştirmeyi hedefleyen bir sanat eğitimi verilmektedir (Gence, 1999). Bu eğitimi alacak olan öğrencinin alan için uygun olup olmadığı konusundaki ölçüm hassas bir dengedir. Çünkü; sanat alanlı fakülteler özellikle az öğrenci kapasiteleri ile eğitiminin kalitesini artırmayı ve bireysel farklılıkların gözetilmesi konusunda daha rahat bir ortam sağlanmasını amaçlamaktadır.

Sanat eğitimi salt beceriye, yeteneğe dayalı bir eğitim değildir; tarihsel gelişim içinde değişen eğitim politikasına paralel olarak önemini korumuş ve gelişmiştir (Katırancı, 2003). Hangi alan olursa olsun birey, kendi potansiyelini ortaya en iyi şekilde çıkaracak sınavlara girmeli ve bu sınavlar ile potansiyeli doğrultusunda seçimler yapmalıdır. Böylece öğrencinin eğitim-öğretim hayatındaki verimliliği artacak mesleki seçimindeki memnuniyet kat sayısı da bu artıştan etkilenecektir. Türkiye'de sanat alanlı fakültelere öğrenci alımı 1900'lü yıllardan bu yana özel yetenek sınavı ile gerçekleşmiştir. Ancak; çağın getirileri ile açılan yeni bölümlerin iç dinamiği gereği sanat alanlı fakültelerin bazı bölümlerine merkezi sınav sistemi ile de öğrenci alımı yapılmaya başladığı bilinmektedir.

Genel anlamda Görsel İletişim Tasarımı Bölümü karakteristik olarak yaratıcılığı ön planda tutan disiplinler arası bir bağlam ortaya koymaktadır. Böyle bir karaktere sahip bölümün yetenek sınavı mı yoksa standart bir merkezi sınav ile mi öğrenci almalı? sorusu zihinleri meşgul edebilmekte ve bu konunun araştırılması hususundaki gereksinimi ortaya koyabilmektedir. Bu doğrultuda; konunun araştırılmasına yönelik ortaya çıkan ihtiyaçtan hareketle, "Türkiye'deki Güzel Sanatlar Fakültelerine özel yetenek sınavı ile yerleştirilen öğrenciler ile merkezi sınav sistemi ile yerleştirilen öğrencilerin başarı durumlarında anlamlı bir fark var mıdır?" sorusunun cevabına ilgili bölümün öğretim elemanları görüşleri ile ulaşımaya çalışımıştır. Bu bağlam ile araştırma Görsel İletişim Tasarımı Bölümleri üzerinden yapılan bir anket çalışmasını kapsamaktadır.

\section{Sanat Eğitimi ve Türkiye'de Sanat Eğitimi Veren Fakülteler}

Hegel'e göre sanat, "ruhun madde içindeki görünümü" dür (Türkdoğan, 1984: 11). Yani sanat ilk bireyin duygularına hitap eder. Herhangi bir sanatsal ortamda birey dolaylı ya da dolaysız yoldan eğitilir. Çünkü görsel sanatlar ilk göze hitap eder. Ardından duyulara yaptığı etki ile bireyin estetik 
bakış açısını şekillendirir. İşte bu görsel sanatlar eğitiminin en genel amacını oluşturur. Görsel sanatlar eğitiminin tanımı da bu amaç doğrultusunda şekillenmiş̧ir. Eğitim bireyin doğumundan ölümüne kadar devam eden bir süreçtir (Kurt, 2008). Bu süreç bireyin kendisini var etmesine olanak sağlar. Eğitim, sadece tanımlanabilecek bir nesne değildir. Aynı zamanda, eğitim; hissedilen, özümsenen ve bir güç haline getirilen bir araç görevi görür (Yıldırım, 2011). Aykut'a göre "genel eğitim kapsamında görsel sanatlar eğitimi; sanatların yasa ve tekniklerini kullanarak bireye estetik kişilik kazandırmayı hedefleyen bir eğitim alanıdı" (Aykut, 2006). Tanımından da anlaşılacağı üzere görsel sanatlar eğitimi yalnızca sanat öğrencileri için bir gereklilik değildir. Hangi alandan, yaştan, cinsiyetten ya da milliyetten olursa olsun her birey günlük yaşamını şekillendirmede kendi estetik yargılarını kullanır. Bu sebeple estetik bakış açısını kazandırmada sanat dolayısıyla sanat eğitimi önemli bir yere sahiptir. Sanatın bireyin yaşamına yaptığı katkıyı küçümseyen her düşünce unutmamalıdır ki bir toplumun kültürünü şekillendiren, gelecek nesillere aktarımını sağlayan en önemli alanlardan biri sanattır. Bu bağlam ile sanat eğitimi verilen kurumların işleyişine dair sürdürdüğü her bir kademe en doğru şekilde düzenlenip uygulamalar o çağın kültürüne yön verileceği düşüncesi kapsamında gerçekleştirilmelidir. Çünkü, "sanat eğitimi; bireyin, bedensel, duygusal, algısal ve zihinsel gelişimi adına, sanat yoluyla gerçekleştirdiği tüm eğitim çabasıdır. Yaşam ve evreni aynı kavrayıp, yansıtma, yaratma ve bir dünya kurma sürecidir" (Timuçin, 2000: 197)

\begin{tabular}{|l|c|}
\hline \multicolumn{1}{|c|}{ Fakülteler } & Sayı \\
\hline Güzel SanatlarFakültesi & 53 \\
\hline Sanat ve Tasarım Fakültesi & 6 \\
\hline Güzel Sanatlarve Tasarım Fakültesi & 4 \\
\hline Güzel Sanatlar, Tasarım ve MimarlıkFakültesi & 3 \\
\hline Sanat Tasarım ve MimarlıkFakültesi & 1 \\
\hline Mimarlık, Tasarımve Güzel SanatlarFakültesi & 1 \\
\hline \multicolumn{1}{|c|}{ TOPLAM } & 68 \\
\hline
\end{tabular}

Tablo I. Türkiye'de Bulunan Sanat Alanlı Fakülteler

Türkiye'de 2015-2016 eğitim öğretim yılı itibari ile 109'u devlet üniversitesi ve 76'sı vakıf üniversitesi olmak üzere, toplam 185 adet üniversite bulunmaktadır (YÖK, 2016). Bunlar içerisinde; Güzel Sanatlar Fakültesi; Güzel Sanatlar Tasarım ve Mimarlık Fakültesi; Sanat ve Tasarım Fakültesi; Güzel Sanatlar ve Tasarım Fakültesi; Sanat Tasarım ve Mimarlık Fakültesi; ve Mimarlık, Tasarım ve Güzel Sanatlar Fakültesi adları ile 68 fakülte bulunmaktadır. Bu 68 
fakültenin 11'i kurulum aşamasında geri kalan 57'si ise öğrencileri ile aktif eğitim-öğretimi sürdürmektedir.

\section{Görsel Illetişim Tasarımı ve Görsel Illetişim Tasarımı Bölümlerine Öğrenci Alım Şekilleri}

Becer, iletişimi "gönderici ve alıcı olarak adlandırılan iki insan ya da insan grubu/kitlesi arasında gerçekleşen bir duygu, düşünce, davranış ve bilgi alışverişi" olarak tanımlamaktadır (Becer, 1997: 11). Çağın en etkili alanlarından birini oluşturan iletişim, toplumsal ilişkilerinde belirleyicisi konumundadır.

Görsel iletişimin temelini oluşturan görme yeteneği, algılamada önemli bir rol oynar. Çünkü tarih içinde görme yeteneği konuşmadan önce gelmiştir (Bingöl, 2010: 37). Bu sebep ile görsel iletişimin başlangıcı olarak ilkel mağara devri resim ve simgeleri kabul edilmektedir. Tasarım alanına göre form elemanları semboller, yazılı metinler, görüntüler, mobilyalar veya mekânlar olarak değişkenlik göstermesine rağmen yapılan faaliyetler görsel organizasyondur. Sanat, diğer alanlardan farklı olarak problemlere çözümler arar. Sanatın görsel çözümlemeler arama sürecine tasarım süreci denilebilir (Bingöl, 2010: 42).

"Görsel Illetişim Tasarımı, teknoloji ve tasarımı birleştirerek iletişim kuran yaratıcı bir süreçtir. Günümüz reklamcılık, tanıtım ve iletişim alanlarında, yeni medyaların doğarak kendi dinamiklerini oluşturması, eski mecraların teknoloji ile daha hızlı, devamlı bir etkileşime geçmesi sonucu tasarımın geleneksel iletişim yöntemleri yetersiz kalmakta ve evrilmektedir. Tüm medyalara, iletişim teknolojilerine, ürün ve hedef kitle arasında kalan tasarım problemine çözüm üretebilecek yeni uzmanlık alanı doğmuştur, bu çok geniş kapsamlı alan; Görsel İletişim Tasarımı'dır" (Gazi, 2016). Türkiye'deki Görsel İletişim Tasarımı Bölümlerinin genel amacı da; medya, reklam, teknoloji ve kitle iletişim sektörleri gibi alanlara hâkim profesyoneller yetiştirmektir.

Türkiye'deki devlet üniversitelerinin dokuzunda görsel iletişim tasarımı bölümü bulunmaktadır. Ancak üç tanesi kurulum aşamasında olduğu için henüz eğitim öğretim hayatına başlamamıştır. Geriye kalan altı üniversitenin beşi merkezi sistem (Dumlupınar Üniversitesi, Eskişehir Osmangazi Üniversitesi, Gazi Üniversitesi, Ondokuz Mayıs Üniversitesi, Sakarya Üniversitesi) biri (Erciyes Üniversitesi) ise özel yetenek sınavı ile öğrenci almaktadır. 


\begin{tabular}{|c|l|l|c|}
\hline & \multicolumn{1}{|c|}{ Üniversite } & \multicolumn{1}{c|}{ Fakülte } & Öğrenci Alım Şekli \\
\hline 1 & Erciyes Üniversitesi & Güzel SanatlarFakültesi & Yetenek Sınavi \\
\hline 2 & Dumlupınar Üniversitesi & Güzel SanatlarFakültesi & Merkezi Sistem \\
\hline 3 & $\begin{array}{l}\text { Eskişehir Osmangazi } \\
\text { Üniversitesi }\end{array}$ & Sanat ve Tasarım Fakültesi & Merkezi Sistem \\
\hline 4 & Gazi Üniversitesi & Güzel SanatlarFakültesi & Merkezi Sistem \\
\hline 5 & Ondokuz Mayıs Üniversitesi & Güzel SanatlarFakültesi & Merkezi Sistem \\
\hline 6 & Sakarya Üniversitesi & Güzel SanatlarFakültesi & Merkezi Sistem \\
\hline 7 & $\begin{array}{l}\text { Abant İzzet Baysal } \\
\text { Üniversitesi }\end{array}$ & Güzel SanatlarFakültesi & Kurulum Aşamasında \\
\hline 8 & $\begin{array}{l}\text { İstanbul Medeniyet } \\
\text { Üniversitesi }\end{array}$ & Sanat ve Tasarım Fakültesi & Kurulum Aşamasında \\
\hline 9 & $\begin{array}{l}\text { Nevşehir Haci Bektaş Veli } \\
\text { Üniversitesi }\end{array}$ & Güzel SanatlarFakültesi & Kurulum Aşamasında \\
\hline
\end{tabular}

Tablo 2. Türkiye'de Görsel İletişim Tasarımı Bölümü Bulunan Üniversiteler ve

\section{5-20I6 Eğitim Öğretim Yılı Öğrenci Alım Şekilleri}

Ülkemizde bulunan Güzel Sanatlar Fakülteleri bölümlerine girmek için uygulanması gereken yol üniversitelere hatta bölümlere göre farklılık gösterebilir. Bu farklıık yetenek sınavlarının her üniversitenin kendi bünyesinde yapıyor olmasından kaynaklıdır. Diğer farklılık ise YÖK kararına bağlı olarak bazı bölümlerin öğrenci alımlarında merkezi sistem ile yapmasından kaynaklanır.

Yetenek; kalıtımla gelen gizil güçlerin eğitim ve çevrenin etkisiyle geliştirilmiş kısmını ifade eder (Arı, 2008: 19). Yetenek Testleri Bireylerin zihinsel ya da akademik yetenekleri hakkında bilgi toplamak amacıyla hazırlanmış araçlardır. Bunlar belirli yaş grupları için değişik biçimlerde hazırlanmış standart testlerdir. Yetenek testleri bireyin potansiyelini ortaya çıkaran testlerdir. Potansiyelinin farkında olan bir öğrenci hayatını yönetmede daha sağlıklı kararlar verebilir. Günümüzde birçok öğrenci potansiyeli dışında alanlarda eğitim almakta ve buna bağlı olarak da sevmediği mesleklerde çalışmak zorunda kalmaktadır. Yetenek testleri kişinin farkında olmadığı gizil güçler dediğimiz özellikleri de ortaya çıkarabildiği için kişinin hayatına dair bir sonraki adımı atmada sağlam bir referans kaynağı olur.

Bilindiği gibi özel yetenek sınavlarında ölçme sonuçlarının büyük bir kısmını öğrenci çizimleri oluşturmaktadır. Bu çizimler; desen, imgesel sınav ya da uzamsal zekayı ölçen soru yönergeleri çerçevesinde gerçekleştirilmektedir. Bu sınavlar; gözlem gücü, çizgi gücü, hayal gücü, uzamsal düşünme gücü gibi yeterlikleri ölçmek için birer araçtır. (Özmutlu, 2014: 97).

Ülkemizde yetenek sınavlarına girebilmenin önkoşulu YGS'ye girmiş ve YGS 
puanlarının herhangi birinden en az 140 puan almış olmaktır. ÖSYM'nin 2014 sınav kılavuzunda "Güzel Sanatlar Fakültelerinin Resim ve Heykel bölümlerinde okumak isteyenlerin, üstün yeteneklerinin saptanması için ilgili yükseköğretim kurumlarına doğrudan başvurmaları gerekmektedir. Bu adayların değerlendirme ve seçme işlemleri Yükseköğretim Kurulunun 27.11.1985 tarihli kararı uyarınca ilgili rektörlüklerin oluşturduğu komisyonlar tarafından yapılacaktır" denmektedir.

Yerleştirmeye esas olan puanın hesaplanması için aşağıdaki üç puan belli ağırlıklarla çarpılarak toplamı alınır:

a) ÖYSP Standart Puanı (ÖYSP-SP)

b) Ortaöğretim Başarı Puanı

c) 2015-YGS Puanı (YGS-P) (YGS puanlarının en büyüğü)

Özel Yetenek Sınavı Puanının (ÖYSP) ağırlıklandırmaya girebilmesi için bu puanların standart puanlara çevrilmesi gerekir. ÖYSP'lerin standart puana çevrilmesi için önce ÖYSP dağılımının ortalaması ve standart sapması hesaplanacak, daha sonra da her aday için aşağıdaki formül kullanılarak ÖYSP Standart Puanı hesaplanır.

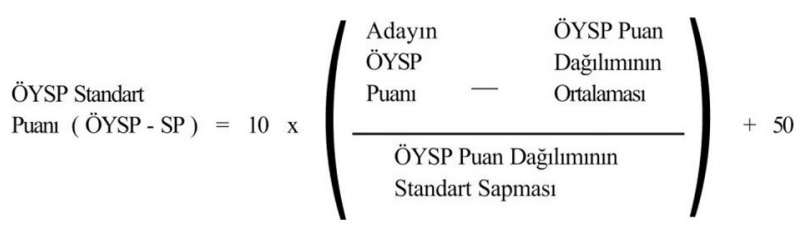

Şekil I. Merkezi Sınav Sistemi Puan Hesaplama Formulü

Ülkemizde Güzel Sanatlar Fakültesindeki bölümlere öğrenci alımlarının diğer bir şekli merkezi sistem ile yapılmaktadır. Yök tarafından alınan kararlar doğrultusunda ÖSYM'nin yaptığı sınav sonucuna göre öğrenciler yetenek sınavı olmaksızın ilgili bölümlere yerleştirilmektedir. Bu süreç Güzel Sanatlar Fakültelerinin ilgili bölümlerine girmek isteyen öğrenciler için, sosyal, fen, sağlık yada eğitim fakültelerine girmek isteyen öğrenciler ile aynı şekilde işlemektedir. Ösym'nin sınav kılavuzunda merkezi sistem ile yerleştirme YGS'de uygulanan testlere verilen cevaplar, her test için ayrı ayrı değerlendirmeye alınır. Adayların; Türkçe, Sosyal Bilimler, Temel Matematik ve Fen Bilimleri testlerinden her biri için birer standart puanı hesaplanır (ÖSYM, 2015). 


\section{Yöntem ve Bulgular}

Bu araştırmanın modeli olarak tarama modeli benimsenmiştir. Tarama modellerinde "araştırmaya konu olan olay, birey ya da nesne kendi koşulları içinde olduğu gibi tanımlanmaya çalışılır" (Karasar, 2009: 77). 5'li likert tipi anket kullanılarak betimsel analiz yapılmıştır. Anketin geçerlilik güvenilirliğini sağlamak için anket soruları 2 öğrenci, 3 alan uzmanı ve 1 Türkçe öğretmenine okutulmuştur. Anketin uygulama alanı Türkiye' de bulunan 6 üniversitedeki Görsel İletişim Tasarımı Bölüm öğretim elemanlarıdır. 68 kişiden oluşan bu evrenin çeşitli iletişim eksikliklerinden kaynaklı sebepler dolayısıyla yalnızca 54 'üne ulaşılabilmiş ve 30 kişiden yanıt alınmıştır. Ankette 13 kritere odaklanılmıştır. Bu 13 kriter öğretim elemanları tarafından hem yetenek sınavı hem de merkezi sınav ile alınan öğrenciler için ayrı ayrı derecelendirilmiştir. Bu kriterler;

1.Alan derslerine yönelik ilgi

2.Uygulamalı derslerdeki başarı

3. Teorik derslerdeki başarı

4. El-göz-beyin kordinasyonu

5. İmgesel düşünebilme becerisi

6. Yaratıcilık

7. Ders kapsamında karşılaşılan problemlere çözüm getirme becerisi

8. Teorik derslerdeki sınıf içi uyumu/katılımı

9. Uygulama derslerindeki sınıf içi uyumu/katılımı

10. Sağlıkıı iletişim kurma becerisi

11. Alan ile ilgili sosyal aktivitelere (sergi, çalıştay, panel vb.) Katılım oranı

12. Duygu ve düşüncelerini eleştirilebilme kaygısı gütmeden ifade edebilme becerisi

13. Alana yönelik olumlu gelecek planları

Anket derecelendirmelerinde; 1=Hiç Katılmıyorum, 2=Katılmıyorum $3=$ Kararsızım, 4=Katılıyorum , 5=Kesinlikle Katılıyorum anlamına gelmektedir. 


\begin{tabular}{|l|c|c|}
\hline \multicolumn{1}{|c|}{ Kriterler } & $\begin{array}{c}\text { Yetenek } \\
\text { Sinavı }\end{array}$ & $\begin{array}{c}\text { Merkezi } \\
\text { Sinav }\end{array}$ \\
\hline Alan derslerine yönelikilgi & $\% 79$ & $\% 16$ \\
\hline Uygulamalı derslerdekibaşarı & $\% 86$ & $\% 13$ \\
\hline Teorik derslerdeki başarı & $\% 29$ & $\% 59$ \\
\hline El-göz-beyin koordinasyonu & $\% 83$ & $\% 10$ \\
\hline İmgesel düşünebilme becerisi & $\% 76$ & $\% 3$ \\
\hline Yaratıcılık & $\% 76$ & $\% 6$ \\
\hline Ders kapsamındakarşlaşılan problemlere çözüm getirme becerisi & $\% 49$ & $\% 13$ \\
\hline Teorik derslerdeki sınıfiçi uyumu/katılımı & $\% 32$ & $\% 52$ \\
\hline Uygulama derslerindeki sınıf içi uyumu/katılımı & $\% 76$ & $\% 26$ \\
\hline Sağlılıiletişim kurmabecerisi & $\% 53$ & $\% 33$ \\
\hline Alan ile ilgili sosyal aktivitelere (sergi, çalıştay, panel vb.) katılımoranı & $\% 72$ & $\% 12$ \\
\hline $\begin{array}{l}\text { Duygu ve düşüncelerini eleştirilebilme kaygısı gütmeden ifade edebilme } \\
\text { becerisi }\end{array}$ & $\% 43$ & $\% 13$ \\
\hline Alana yönelik olumlu gelecek planları & $\% 53$ & $\% 16$ \\
\hline
\end{tabular}

Tablo 3. Her Iki Grubun Kriterlerdeki Yüzdelik Başarı Oranları

Tablo 2'ye göre anket bulgularında ankete katılan öğretim elemanlarının belirtilen kriterlere ilişkin oranlar şöyledir;

- Yetenek sınavı ile gelen öğrencilerin alan derslerine yönelik ilgilerini yaklaşık olarak \% 79 oranında başarılı bulurken merkezi sınav ile gelen öğrencilerde bu oran yaklaşık \% 16'dır.

- Yetenek sınavı ile gelen öğrencilerin uygulamalı derslerdeki başarıları oranı yaklaşık olarak \% 86 iken merkezi sınav ile gelen öğrencilerde bu oran yaklaşık \%13'tür.

- Yetenek sınavı ile gelen öğrencilerin teorik derslerdeki başarıları oranı yaklaşık olarak \% 29 iken merkezi sınav ile gelen öğrencilerde bu oran yaklaşık \% 59'dur.

- Yetenek sınavı ile gelen öğrencilerin el-göz-beyin kordinasyonu yaklaşık olarak $\% 83$ oranında başarılı bulurken merkezi sınav ile gelen öğrencilerde bu oran yaklaşık \% 10'dur.

- Yetenek sınavı ile gelen öğrencilerin imgesel düşünebilme becerisini yaklaşık olarak \% 76 oranında başarılı bulurken merkezi sınav ile gelen öğrencilerde bu oran yaklaşık \% 3'tür.

- Yetenek sınavı ile gelen öğrencilerin Yaratıcılık düzeylerini yaklaşık 
olarak \%76 oranında başarılı bulurken merkezi sınav ile gelen öğrencilerde bu oran yaklaşık \% $\sigma^{\prime}$ dır.

- Yetenek sınavı ile gelen öğrencilerin ders kapsamında karşılaştıkları problemlere çözüm getirme becerisi düzeyini yaklaşık olarak \%49 oranında başarılı bulurken merkezi sınav ile gelen öğrencilerde bu oran yaklaşık \% 13'tür.

- Yetenek sınavı ile gelen öğrencilerin teorik derslerdeki sınıf içi uyum/ katılım düzeylerini yaklaşık olarak \%32 oranında başarılı bulurken merkezi sınav ile gelen öğrencilerde bu oran yaklaşık \% 52'dir.

- Yetenek sınavı ile gelen öğrencilerin uygulama derslerdeki sınıf içi uyum/katılım düzeylerini yaklaşık olarak \%76 oranında başarılı bulurken merkezi sınav ile gelen öğrencilerde bu oran yaklaşık \% 26 'dır.

- Yetenek sınavı ile gelen öğrencilerin Sağlıklı iletişim kurma beceri düzeylerini yaklaşık olarak \%53 oranında başarılı bulurken merkezi sınav ile gelen öğrencilerde bu oran yaklaşık \% 33'tür.

- Yetenek sınavı ile gelen öğrencilerin alan ile ilgili sosyal aktivitelere (sergi, çalıştay, panel vb.) Katılım oranı yaklaşık olarak \%72 iken merkezi sınav ile gelen öğrencilerde bu oran yaklaşık \%12'dir.

- Yetenek sınavı ile gelen öğrencilerin duygu ve düşüncelerini eleştirilebilme kaygısı gütmeden ifade edebilme becerisi yaklaşık olarak \% 43 oranında başarılı bulurken merkezi sınav ile gelen öğrencilerde bu oran yaklaşık \%13'tür.

- Yetenek sınavı ile gelen öğrencilerin alana yönelik olumlu gelecek plan oranını yaklaşık olarak \% 53 başarılı bulurken merkezi sınav ile gelen öğrencilerde bu oran yaklaşık \% 16 'dır.

\section{Sonuç}

Anket uygulamasından elde edilen verilere göre; Yetenek Sınavı ile alınan öğrenciler, alan derslerine yönelikilgi, uygulamalı derslerdeki başarı, el-gözbeyin koordinasyonu, imgesel düşünebilme becerisi, yaratıcılık, uygulama derslerindeki sınıf içi uyumu/katılım, alan ile ilgili sosyal aktivitelere (sergi, çalıştay, panel vb.) katılım oranı kriterlerinde Merkezi Sistem ile alınan öğrencilerden daha başarılı olduğu sonucuna ulaşılmışır. Sağlıklı iletişim kurma becerisi ve alana yönelik olumlu gelecek planları kriterlerine dair oranlar çok büyük fark içermese de yine yetenek sınavı ile alınan öğrenciler merkezi sınav ile alınan öğrencilerden daha başarılı bulunmuştur. 
Ders kapsamında karşılaşılan problemlere çözüm getirme becerisi ve duygu, düşüncelerini eleştirilebilme kaygısı gütmeden ifade edebilme becerisi kriterleri oranlarında Yetenek Sınavı ile alınan öğrenciler her ne kadar Merkezi Sınav ile alınan öğrencilerden daha yüksek bir başarı oranına sahip olsa da bu oran \%50'nin altında kalması sebebiyle genel anlamda söylenebilir ki bu iki kriterde her iki grup öğrencide verilen eğitimde istenilen sonuca ulaşmamaktadır. Teorik derslerdeki başarı ve teorik derslerdeki sınıf içi uyum/katılım kriterlerinde ise Merkezi Sitem ile alınan öğrenciler yetenek sınavı ile alınan öğrencilerden daha başarılı bulunmuşlardır.

Ulaşılan tüm bu sonuçlar göz önüne alındığında belirlenen 13 kriterden 11 'inde yetenek sınavı ile alınan öğrenciler başarılı olurken yalnızca 2 kriterde Merkezi Sınav Sistemi ile alınan öğrenciler başarılı bulunmuştur. Bu bağlam ile bu araştırma, Türkiye'deki Görsel Illetişim Tasarımı Bölümü öğretim elemanları bölümün vizyon ve amaçları göz önüne alındığında öğrenci alımlarının Yetenek Sınavı ile gerçekleşmesi ile daha başarılı sonuçlar elde edileceği görüşündedirler. 


\section{Kaynakça}

Arı, N. E. O. (2008). Türkiye'de Seramik Eğitimi Veren Yüksek Öğrenim Kurumlarına Öğrenci Seçmede Uygulanan Sınavların Yeterliliği, Yayımlanmamış Yüksek Lisans Tezi, Gazi Üniversitesi Eğitim Bilimleri Enstitüsü, Ankara.

Aykut, A. (2006). “Günümüzde Görsel Sanatlar Eğitiminde Kullanılan Yöntemler”. Erciyes Üniversitesi Sosyal Bilimler Enstitüsü Dergisi, 21, 33-42.

Becer, E. (1997). Iletişim ve Grafik Tasarım. Ankara: Dost Kitabevi Yayınları.

Bingöl, B. (20/0). Lisans Düzeyindeki Görsel Illetişim Tasarımı Eğitiminde Çoklu Ortam (Multimedya) Kullanımı: Ankara'daki Görsel Illetişim Tasarımı Bölümlerinin Incelenmesi, Yayımlanmamış Doktora Tezi, Gazi Üniversitesi Eğitim Bilimleri Enstitüsü, Ankara.

Gence, C. (1999). “Güzel Sanatlar Fakültesi Mezunları ve Sanat Öğretmenliği”. Milli Eğitim Dergisi, I42, 6I-6.

Karasar, N. (2009). Eğitimde Araştırma Yöntemleri. Ankara: Nobel Yayıncılık.

Katırancı, M. (2003). Sanat Eğitimi Nasıl Olmalıdır. Milli Eğitim, I60(I4).

Kurt, i. (2008). Yetişkin Eğitimi, Ankara: Asil Yayın Dağıtım.

Özmutlu, A. (20/4). Kendine Özgü Ölçme ve Değerlendirme Illkeleri Ve Kriterleri Açısından Güzel Sanatlar Eğitimi Bölümü Resim-Iş Eğitimi Anabilim Dallarının Giriş/Özel Yetenek Sınavları, Doktora Tezi, Ondokuz Mayıs Üniversitesi Eğitim Bilimleri Enstitüsü, Samsun.

Timuçin, A. (2000). Estetik. İstanbul: Bulut Yayınları.

Türkdoğan, G. (1984). Sanat Eğitimi Yöntemleri. Ankara: Kadıŏlu Matbaası.

Yıldırım, A. (20I I). Eleştirel Pedagoji; Paul Freire ve Ivan Illich’in Eğitim Anlayışı Üzerine. Ankara: Anı Yayıncılık.

\section{İnternet Kaynakları}

Internet: Gazi (20/6). Gazi Üniversitesi Güzel Sanatlar Fakültesi Web Sayfası, http:// gsf-git.gazi.edu.tr/posts/view/title/gorsel-iletisim-tasarimi-nedir\%3F-90942, adresinden 15 Eylül 2016’da alınmıştır.

Internet: ÖSYM. (20I5). Öğrenci Seçme Ve Yerleştirme Sistemi (ÖSYS) Kılavuzu. http:// www.osym.gov.tr/TR,46/20I5-osys-kilavuz-ve-basvuru-bilgileri.html, adresinden I5 Eylül 2016'da alınmıştır. 
Internet: YÖK (2016). Yüksek Öğretim Kurumu Web Sayfası. http://www.yok.gov.tr/web/ guest/universiteler;jsessionid=D0 IAIE2CDD656F68F5329E4C3A7F8495. adresinden 15 Eylül 2016'da alınmıştır. 